\title{
Effect of host species on larval growth differs between instars: The case of a geometrid moth (Lepidoptera: Geometridae)
}

\author{
Helen VELLAU, SiIRI-LiI SANDRE and ToOmas TAMMARU \\ Department of Zoology, Institute of Ecology and Earth Sciences, Vanemuise 46, University of Tartu, EE-51014, Estonia; \\ e-mails: helen.vellau@ut.ee; siiri-ly@ut.ee; toomas.tammaru@ut.ee
}

Key words. Lepidoptera, Geometridae, Ematurga atomaria, larval performance, body size, reaction norm, host plant quality, Calluna, Vaccinium

\begin{abstract}
Although the effects of host plant quality on the performance of polyphagous herbivores are largely uniform across insect taxa, there are various exceptions to this rule. In particular, there are scattered reports of cases in which the relative quality of different hosts differs among larval instars of a single insect species. Such cases are explained either in terms of differences in the susceptibility of different aged larvae to plant defences or, alternatively, age-specific nutritional demands. Here we report the results of experiments that show that young larvae of the polyphagous common heath moth Ematurga atomaria (Lepidoptera: Geometridae) consistently attain higher weights on common heather Calluna vulgaris than bilberry Vaccinium myrtillus, whereas the rank order of these host plants is reversed in the final larval instar. Phytochemical analyses showed that differences in nutrient content of these plants are not likely to explain the observed pattern. Instead, the results are more consistent with the idea that the greater chemical defence of bilberry has a relatively stronger influence on young than old larvae.
\end{abstract}

\section{INTRODUCTION}

Despite the largely uniform effects of various plant traits on herbivore performance (Scriber \& Slansky, 1981; Price, 1997; Chown \& Nicolson, 2004; Schoonhoven et al., 2007), the relative quality of a particular host may sometimes still be different for differently aged larvae of the same insect species. In other words, young larvae may perform better on host A than on host B while the situation could be the opposite for old larvae. Formally speaking, in such a case we are faced with a larval age by host quality interaction (age*host, hereafter) for herbivore performance. Documented examples of this in moths include Mnesampela privata feeding on various Eucalyptus species (Steinbauer \& Matsuki, 2004), Orgyia leucostigma feeding on balsam fir foliage of different ages (Johns et al., 2009) and Thaumetopoea pityocampa on various species of Pinus (Hodar et al., 2002). In more general terms, these results are supported by the frequent observation that the final larval instars of various insects are able to thrive on a wider array of host plant species than their younger conspecifics (Schoonhoven et al., 2007).

When looking for proximate explanations for such age*host interactions, it is reasonable to assume that nutritional requirements (primarily, in terms of nitrogen and carbon content) of larvae may change as they age. In particular, Bernays \& Chapman (1994) propose (the ontogenetic hypothesis sensu Pinault et al., 2009) that during their early stages, larvae primarily need nitrogen (protein), but in the later stages carbohydrates are more essential because of the energy required for metamorphosis and adult life. Indeed, Stockhoff (1993) confirms this prediction for Lymantria dispar: proceeding from early to late instars, feeding preference of the larvae shifts away from high protein food. Consistently, Joseph et al. (1993) found that neonate larvae of this species grew faster on a high nitrogen diet whereas fourth instar larvae performed better on a diet with low nitrogen levels. A similar result is reported by Hodar et al. (2002) who found that the survival of first-instar larvae of Thaumetopoea pityocampa is poorer than that of late instar larvae fed low-nitrogen food. To our knowledge, there is no empirical evidence of a pattern opposite to the one predicted by the ontogenetic hypothesis.

In addition to the age-dependent nutrient demand hypothesis, a moderate number of studies support the idea that young larvae are more susceptible to the chemical defences of their host plants (secondary metabolites such as terpenoids, phenols etc.). In particular, substances proposed to differentially affect larvae of different ages include phenolic glycosides (Lindroth \& Bloomer, 1991) and oils (Steinbauer \& Matsuki, 2004). Moreover, there is a possibility of interactions between the effects of nutrients and defensive chemicals. For example, Behmer et al. (2002) report that tannic acid has a stronger deterrent effect when food contains a large excess of carbohydrates relative to protein, whereas locusts tolerated relatively large amounts of tannic acid in protein-rich diets. As the concentrations of both protein and carbohydrate in plant tissues typically change in the course of a season (Stamp \& Bowers, 1990; Riipi et al., 2002), it is justified to presume that the effect of tannin as a determinant of diet quality may vary in the course of larval development.

In brief, there is some evidence of interactions between larval age and host quality in the herbivore growth performance, as well as some reasonably well supported causal hypotheses. Nevertheless, the empirical evidence 
still remains fragmentary both in terms of insect taxa involved and host plant characteristics studied.

In the present paper, we report the results of a largescale laboratory experiment on Ematurga atomaria, which revealed a consistent age*host interaction determining the growth of the larvae of this geometrid moth. To evaluate some of the possible causes, we performed phytochemical analyses on the two host plants (bilberry and heather) used and present results that conflict with the ontogenetic hypothesis of Bernays \& Chapman (1994): bilberry, which contains more nitrogen is the superior host for old but not young larvae. The results conform more with the idea that young larvae are more susceptible to plant defences: higher concentrations of tannins and polyphenols were found in bilberry, the plant less suitable for young larvae.

\section{MATERIAL AND METHODS}

\section{Study species}

This study was performed on the larvae of the common heath moth, Ematurga atomaria L. (Lepidoptera: Geometridae), a day-flying lepidopteran of about $2.6 \mathrm{~cm}$ in wing span. This widespread and common species is found in various habitats across Europe, but is particularly abundant on moors and heaths. The highly polyphagous and colour-polymorphic larvae (Leraut, 2009; Sandre et al., 2013) are solitary and invariably go through five instars (Vellau \& Tammaru, 2012). In northern Europe, this species is univoltine and larvae are present in July and August. The larvae are external solitary feeders on leaves of their host plants; the cryptic larvae tend to move very little and therefore it is unlikely they actively switch between host individuals (pers. observ. of the authors).

Host plants used in this study, common heather Calluna vulgaris, L. and bilberry Vaccinium myrtillus, L. (both Ericaceae) are dwarf shrubs abundant on moors and in woodlands in Northern Europe. Both species are commonly used as hosts by E. atomaria larvae in the study area (Porter, 1997).

\section{Experimental design}

The data on the growth of E. atomaria larvae come from a rearing experiment in which the larvae were reared on two host species in 2008 and 2009. In 2008, the offspring of 75 wild caught females was randomly divided between two treatment groups, with one group reared to pupation on bilberry $V$. myrtillus and the other on common heather $C$. vulgaris. The laboratory population in 2009 consisted of the offspring of the individuals reared in 2008: 13 males were each mated with one and 48 with two females, which resulted in a total of 109 broods. Once again, the offspring of the resulting half-sib and full-sib families were divided between the two host plants: 12 larvae from each brood were reared on bilberry and three on heather. These experiments were part of a quantitative genetics study of body size and larval colouration the results of which have been published or will be published separately (Sandre et al., 2013; and in prep.)

The larvae ( $\mathrm{N}=325$ in $2008, \mathrm{~N}=1,428$ in 2009) were reared individually in transparent $50 \mathrm{ml}$ plastic vials at $22^{\circ} \mathrm{C}$ and provided with fresh food ad libitum every three days. There were about 4 to 7 leaves on the sections of shoots of $V$. myrtillus and hundreds of leaves on those of $C$. vulgaris. The shoots were collected at random so it is likely the larvae experienced a level of variation in leaf quality comparable to that occurring in the field. Larval mortality was relatively low (ca $18 \%$ in both years) and not significantly different on the two host plants. The vials were randomised on rearing trays with respect to brood (offspring of a particular female) and host plant. For all larvae, development times to the end of the fourth instar and duration of the fifth instar were determined by inspecting the larvae daily. The larvae were weighed at the end of the fourth instar just prior to the last moult (Esperk \& Tammaru, 2004) and the pupae weighed and sexed.

\section{Phytochemical analyses of host plants}

The plants for phytochemical analyses (both species) were collected on July 11 and August 3, 2011, and July 13, July 26 and August 6, 2012 from the same locations as the host plants used for rearing the larvae in 2008 and 2009. Larvae of E.atomaria are in the early and late stages of their development in July and August, respectively. As the chemical content of plants may depend on weather, all sampling in both 2011 and 2012 was done in similar weather conditions (cloudless sky, air temperature around $25^{\circ} \mathrm{C}$ ). As the phytochemical studies were prompted by the results of the analysis of larval growth they were done on plants collected in years different from those in which the larvae were reared (2008 and 2009). The possibility of variation in leaf chemistry between years is well known (Krischik \& Denno, 1983) and for $V$. myrtillus (Laine \& Henttonen, 1993), in particular. However, by collecting data for two seasons we were able to estimate between-year variation in phytochemistry and so mitigate the problem of non-synchronous measurements on larval performance and chemistry of the host plants.

At each sampling event, six whole plants of both species were collected and the leaves randomly separated from the stalks in the laboratory and then dried in the dark at $27^{\circ} \mathrm{C}$ for eight days. Dry leaves were homogenised mechanically and then the content of nitrogen, carbon, polyphenols and tannins, i.e., compounds that are known to have a major effect on larval performance, determined. Nitrogen and carbon concentrations were measured using a 2400 Series II CHNS/O analyzer (PerkinElmer, Waltham, MA, USA). The total tannin content was estimated using the method of Price \& Butler (1977) and total polyphenol content the method of Swain \& Hillis (1959). Detailed descriptions of analyses are available from the authors on request.

\section{Data analysis}

Larval and pupal weights as well as development times were analyzed separately for the two periods as we had data for the development up to the end of the $4^{\text {th }}$ instar and for the $5^{\text {th }}$ instar. Respective mixed ANOVA models included two fixed factors (host and sex) and two random effects: brood (i.e., the offspring of a particular female) and brood*host interaction. The interaction term was included in order to account for possible amongbrood differences in plant suitability and treat a brood (rather than an individual) as an independent observation when testing for the effect of the host. This was achieved by using the Kenward-Roger method for estimating denominator degrees of freedom (Kenward \& Roger 1997).

Growth rate of the first four instars was calculated as (weight at the end of fourth instar $)^{1 / 3} /$ development time and that of the fifth instar as (pupal weight) $)^{1 / 3}-$ (weight at the end of fourth instar $)^{1 / 3}$ )/development time. Given the data on growth allometry of lepidopteran larvae (Tammaru \& Esperk, 2007), this transformation can be used to linearize the growth trajectories, which is desirable when comparing the growth of different instars. Growth rates were analyzed using mixed ANOVA with three fixed factors (sex, host and age). There were two records of growth rate in this model (two ages: first four instars combined, and last instar) for each individual, with the testing for an age*host interaction the primary objective of this analysis. Iden- 


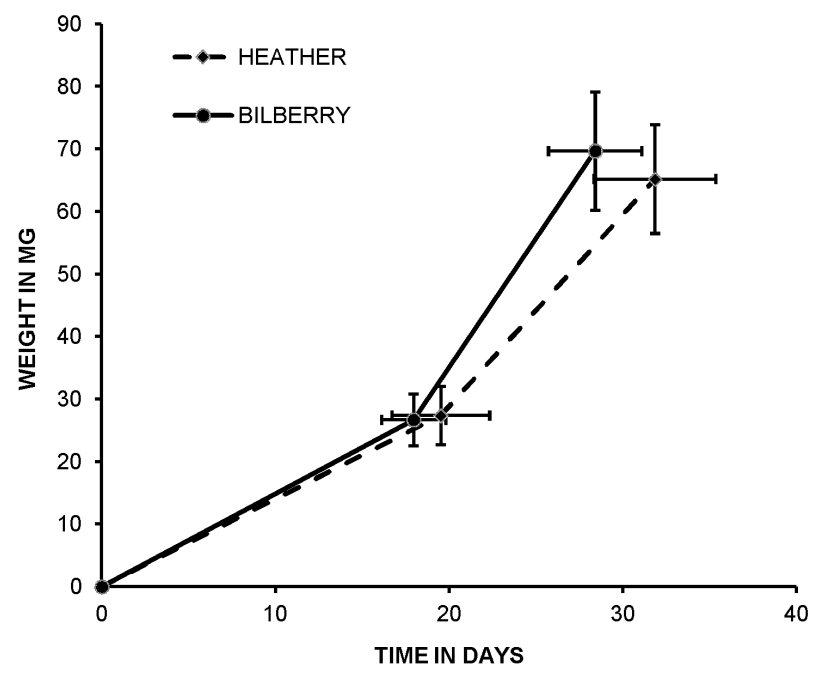

Fig. 1. Growth schedules of larvae fed on heather or bilberry. Development time and body weight (averaged over both years) are recorded at the end of the fourth (penultimate) instar and after pupation. The slopes of the continuous and dashed lines illustrate growth rates. Error bars indicate standard deviation.

tity of the larva was included in the model as a random factor in order to account for repeated measurements on individual larvae. Analyses were conducted using SAS ver 9.2 (SAS Institute, 2009).

The nitrogen, carbon, tannin and polyphenol contents of the host plants for each species and whether sampled early or late in the season were analyzed using a factorial ANOVA in STATISTICA ver 10 for Windows (StatSoft, Inc., 2011).

\section{RESULTS}

\section{Growth of larvae}

Larvae fed on heather were consistently heavier at the end of their fourth instar than those reared on bilberry (the ratio of weights on the two plants was 1.06 in 2008 and 1.03 in 2009; Table 1). In contrast, the opposite was recorded for pupal weights as the pupae of insects reared on bilberry were 1.04 (2008) or 1.09 (2009) times heavier. By way of illustration we present the statistical results for each developmental stage or "age" (Table 1). Consistently, a combined analysis of the two stages (analogous to that in Table 3) revealed a highly significant host*age interaction $(\mathrm{p}<0.001$, in both 2008 and 2009).

Development times were similar in both years (Fig. 1): larvae took longer to develop up to the end of fourth instar and in the last instar on heather and females took longer to develop than males in both age classes (Table 2 ). In a combined analysis of the two developmental stages, the respective host*age interaction was significant (2008: $\mathrm{p}=0.002 ; 2009: \mathrm{p}<0.001$ ).

The response of females and males to the different host plants were similar as in all the analyses of size and development time, the sex*host interaction was significant only once (pupal weight in 2009, Table 1) and even then the effect was qualitatively consistent in the two sexes (just slightly stronger in females). The weight of fourth instar larvae was lower in 2008 (relative differences in yearly means 1.06 times for heather and 1.09 for bilberry), perhaps because the rearing experiment started

TABLE 1. Results of mixed ANOVAs of the effects of host plant and sex on the weights of E. atomaria reared on two host plants (bilberry vs. heather). Brood (offspring of a particular female) and brood*host interaction were treated as random factors. The two host plants had opposite effects on the two age classes (Fig. 1).

\begin{tabular}{|c|c|c|c|c|c|}
\hline & & \multicolumn{2}{|c|}{ Final weight of fourth instar } & \multicolumn{2}{|c|}{ Pupal weight } \\
\hline & & $F_{\text {ddf }}$ & $\mathrm{P}$ & $\mathrm{F}_{\mathrm{ddf}}$ & $\mathrm{P}$ \\
\hline \multirow{3}{*}{2008} & Host plant & $6.7_{62.8}$ & 0.012 & $11.42_{273}$ & $<0.001$ \\
\hline & Sex & $48.07_{319}$ & $<0.001$ & $181.81_{303}$ & $<0.001$ \\
\hline & Host plant*sex & $0.28_{316}$ & 0.56 & $0.07_{292}$ & 0.79 \\
\hline \multirow{3}{*}{2009} & Host plant & $13.97_{1,319}$ & $<0.001$ & $140.53_{46.8}$ & $<0.001$ \\
\hline & Sex & $290.26_{1,341}$ & $<0.001$ & $362.74_{1,230}$ & $<0.001$ \\
\hline & Host plant*sex & $0.29_{1,336}$ & 0.59 & $9.75_{1,209}$ & 0.002 \\
\hline
\end{tabular}

TABLE 2. Results of mixed ANOVAs of the effects of host plant and sex on the development times of larvae fed on bilberry or heather, with brood and brood*host as random effects.

\begin{tabular}{|c|c|c|c|c|c|}
\hline & & \multicolumn{2}{|c|}{ Time taken to reach the last instar } & \multicolumn{2}{|c|}{ Time spent in the last instar } \\
\hline & & $\mathrm{F}_{\mathrm{ddf}}$ & $\mathrm{P}$ & $\mathrm{F}_{\mathrm{ddf}}$ & $\mathrm{P}$ \\
\hline \multirow{3}{*}{2008} & Host plant & $43.81_{65.7}$ & $<0.001$ & $25.15_{62.3}$ & $<0.001$ \\
\hline & Sex & $16.96_{303}$ & $<0.001$ & $79.69_{300}$ & $<0.001$ \\
\hline & Host*Sex & $0.52_{288}$ & 0.47 & $0.77_{281}$ & 0.38 \\
\hline \multirow{3}{*}{2009} & Host plant & $37.63_{52}$ & $<0.001$ & $428.94_{70.8}$ & $<0.001$ \\
\hline & Sex & $34.96_{1,358}$ & $<0.001$ & $209.5_{1,331}$ & $<0.001$ \\
\hline & Host*Sex & $0.16_{1,350}$ & 0.69 & $0.06_{1,318}$ & 0.81 \\
\hline
\end{tabular}



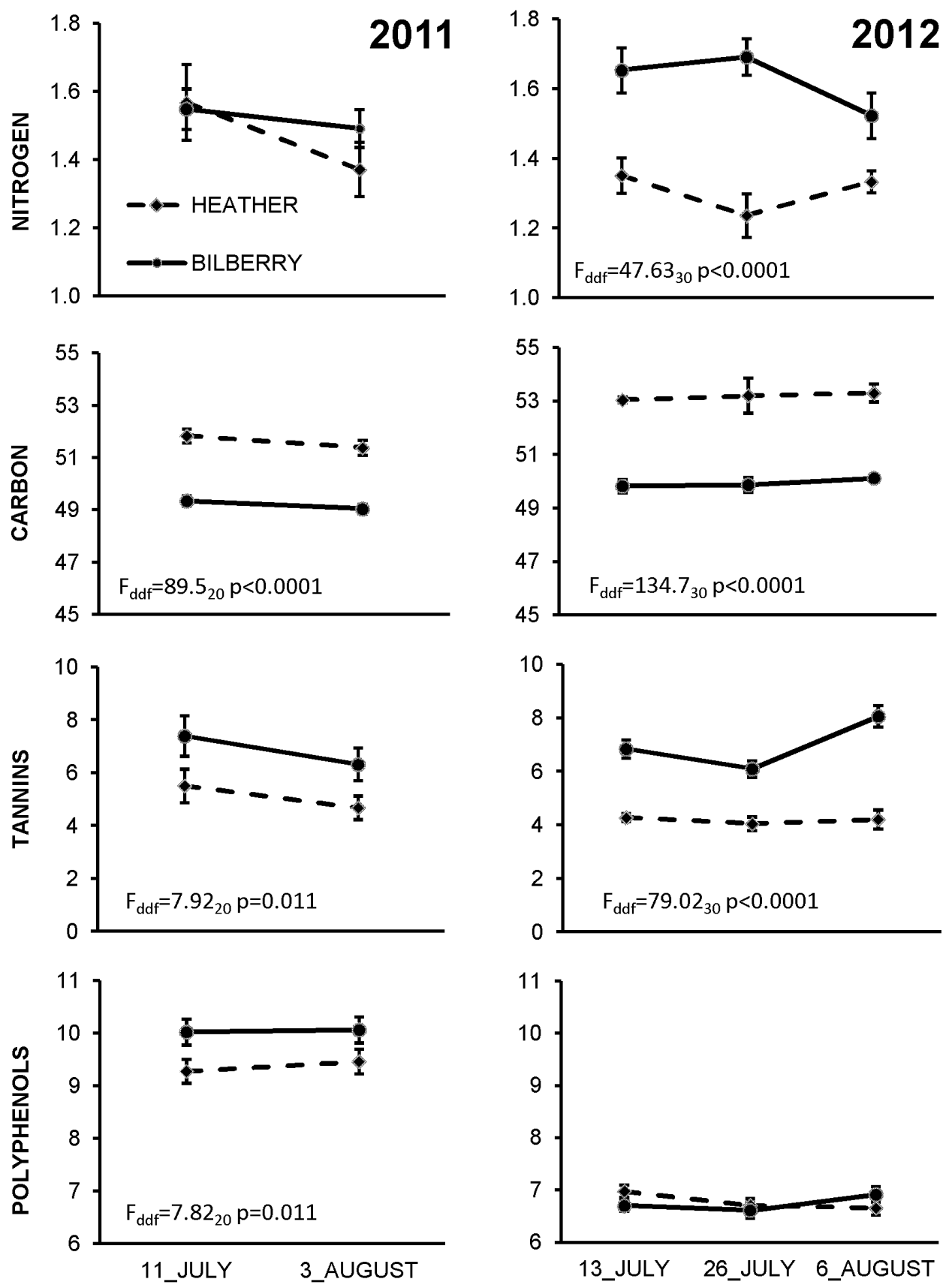

Fig. 2. Differences between the species and seasonal changes in the chemical composition in terms of nitrogen, carbon, tannins and polyphenols recorded for heather and bilberry. Significant differences between plants are presented on the graphs; the only significant temporal trend is discussed in Results. Y-axis is percentage of plant dry mass. Error bars indicate standard errors.

later that year (eggs hatched 13 to 18 June 2008 vs 5 to 10 June 2009), indicating the possibility of a phenological change in host plant quality. Interestingly, the pupal weights were greater in 2008 (relative differences were 1.07 for heather and 1.02 for bilberry).

Consistently, in both years there was a significant age*host interaction for growth rates (Table 3) and individuals fed on bilberry generally had higher growth rates. Ratios of the growth rates on the two plants were 1.07 for first four instars vs 1.19 for the last instar in 2008, with respective values being 1.03 and 1.39 in 2009 , i.e., this difference was more pronounced in the last instar.

\section{Plant parameters}

Chemical composition of the plants and its changes during the season differed slightly between 2011 and 2012; nevertheless, the results were reasonably consistent in these two years (Fig. 2). In particular, the nitrogen content was higher (not significantly so in 2011) and carbon content lower in bilberry than in heather and the content of tannins was consistently higher in bilberry. The differences in the polyphenol content of the two plants were small and inconsistent (Fig. 2).

Temporal trends in chemical composition of the plants were weak (Fig. 2): there were no significant differences between sampling dates in 2011 ( $p>0.1$ for all time*host 
TABLE 3. Results of mixed ANOVAs of the effects of host plant and larval age on growth rates of larvae reared on bilberry or heather, with the identity of a larva included as a random factor to account for repeated measurements on a single individual. "Age" had two levels in the analysis: first four instars combined and last instar.

\begin{tabular}{lcccc}
\hline & \multicolumn{2}{c}{ Growth rates in 2008 } & \multicolumn{2}{c}{ Growth rates in 2009 } \\
\cline { 2 - 3 } \cline { 5 - 5 } Age & $\mathrm{F}_{\text {ddf }}$ & $\mathrm{P}$ & $\mathrm{F}_{\text {ddf }}$ & $\mathrm{P}$ \\
Host & $1019_{323}$ & $<0.001$ & $6909_{1374}$ & $<0.001$ \\
Sex & $88.7_{323}$ & $<0.001$ & $340.6_{1374}$ & $<0.001$ \\
Age*host & $11.5_{323}$ & 0.0008 & $13.2_{1374}$ & 0.003 \\
\hline
\end{tabular}

interaction terms). In 2012, the only significant $\left(\mathrm{F}_{\mathrm{ddf}}=\right.$ $3.77_{30}, \mathrm{p}=0.038$ ) time*host term was for tannin content (Fig. 2).

\section{DISCUSSION}

We recorded a clear case of an age*host interaction, which was consistent between years and sexes. In particular, at the end of their penultimate instar, the larvae of $E$. atomaria fed on heather were heavier than those reared on bilberry; whereas the reverse was the case when the insects reached the pupal stage. Nevertheless, irrespective of developmental stage, larvae fed on bilberry took less time to complete their development. Bilberry was undoubtedly the superior host for last instar larvae as inferior host quality typically leads to both lower final weight and prolonged development (Tammaru, 1998; Awmack \& Leather, 2002; Coley et al., 2006). For this reason, the evidence is somewhat conflicting with respect to the relative quality of the two hosts for young instar larvae (higher weights associated with longer development). Overall, however, it is indisputable that the responses of growth parameters of the differently aged larvae reared on the two host plants were different. In particular, the growth rates of young larvae differed only slightly on the two hosts whereas those of the last larval stage differed considerable.

Our results cannot be easily explained in terms of the ontogenetic hypothesis (Bernays \& Chapman, 1994), which ascribes the age*host interaction to the different nutritional demands of differently aged larvae. Inconsistent with the ontogenetic hypothesis, young larvae performed relatively better on plants with low nitrogen content as the period of developments of those reared on bilberry was shorter than on heather (see Lähdesmäki et al., 1990, for a similar result). Moreover, following Bernays \& Chapman (1994), the difference in carbon content of the two plants should have resulted in the older larvae performing better on the more carbon rich heather, which is the opposite of what we recorded. The seasonal trend in carbon content was weak and very similar in both years for both plants, and could not therefore have contributed to the pattern. The slight phenological differences in phytochemical parameters recorded in the present study (Fig. 2) are likely due to the dates on which the samples were collected in the second half of summer. Indeed, in woody plants, the changes in chemical composition of the leaves are typically much more rapid at the beginning of a season (see e.g. Osier et al., 2000; Riipi et al., 2004; Gripneberg et al., 2007 for studies on various trees, and Jalal et al., 1982, and Laine \& Henttonen, 1993 for some data on $V$. myrtillus and C. vulgaris, respectively).

The results of our study are more consistent with the possibility that differently aged larvae vary in their tolerance of the defensive compounds produced by plants (Schoonhoven et al., 2007). Indeed, bilberry contained significantly more tannins throughout the season. Tannins are generally considered to be important feeding deterrents, even if the evidence is somewhat controversial (Barbehenn \& Constabel, 2011). As bilberry was shown to be an inferior host for young larvae of E. atomaria, the detected pattern may indicate a higher sensitivity of its earlier life stages to plant defences. Similar results are recorded for Malacosoma disstria by Lindroth \& Bloomer (1991): phenolic glycosides are more effective at delaying the development of young than old larvae.

The correlative data we have is not suitable for unequivocally identifying the causal factors behind the age*host interaction in E. atomaria, but may nevertheless indicate that the explanation is probably more complex than just differences in carbon and nitrogen content. In any case, we believe that this study shows that host plants are not equally suitable for larvae throughout their development, a phenomenon that may be more widespread than previously recognized. Indeed, experiments based on large samples, such as those used in quantitative genetic analyses, and careful monitoring of larval growth are needed to detect the pattern reported. We suspect that similar approaches may well reveal analogous patterns in other systems, with a potential bearing on e.g. the debate about the evolutionary advantages of polyphagy (Bernays \& Chapman, 1994) and host switching (Schoonhoven et al., 2007).

ACKNOWLEDGEMENTS. Authors wish to thank I. Tulva for helping with plant analyses and F. Molleman, A. Tiitsaar and T. Teder for their comments on the manuscript. This study was funded by Estonian Science Foundation grant 9294, targeted financing project SF0180122s08 and the European Union through the European Regional Development Fund (Center of Excellence FIBIR).

\section{REFERENCES}

Awmack C.S. \& Leather S.R. 2002: Host plant quality and fecundity in herbivorous insects. - Annu. Rev. Entomol. 47: 817-844. 
Barbehenn R.V. \& Constabel C.P. 2011: Tannins in plantherbivore interactions. - Phytochemistry 72: 1551-1565.

Behmer S.T., Simpson S.J. \& Raubenheimer D. 2002: Herbivore foraging in chemically heterogenous environments: Nutrients and secondary metabolites. - Ecology 83: 2489-2501.

Bernays E.A. \& Chapman R.F. 1994: Host-plant Selection by Phytophagous Insects. Chapman \& Hall, New York, NY, xiii $+312 \mathrm{pp}$

Chown S.L. \& Nicolson S.W. 2004: Insect Physiological Ecology. Mechanisms and Patterns. Oxford University Press, Oxford, UK, 243 pp.

Coley P.D., Bateman M.L. \& Kursar T.A. 2006: The effects of plant quality on caterpillar growth and defence against natural enemies. - Oikos 115: 219-228.

Esperk T. \& TAMmaru T. 2004: Does the 'investment principle' model explain moulting strategies in lepidopteran larvae? Physiol. Entomol. 29: 56-66.

Gripenberg S., Salminen J.-P. \& Roslin T. 2007: A tree in the eyes of a moth - temporal variation in oak leaf quality and leaf-miner performance. - Oikos 116: 592-600.

Hodar J.A., Zamora R. \& CASTRO J. 2002: Host utilisation by moth and larval survival of pine processionary caterpillar Thaumetopoea pityocampa in relation to food quality in three Pinus species. - Ecol. Entomol. 27: 292-301.

JALAL M.A.F., ReAD D.J. \& HaSlam E. 1982: Phenolic composition and its seasonal variation in Calluna vulgaris. - Phytochemistry 21: 1397-1401.

Johns R., Quiring D.T., Lapointe R. \& Lucarotti C.J. 2009: Foliage-age mixing within balsam fir increases the fitness of a generalist caterpillar. - Ecol. Entomol. 34: 624-631.

Joseph G., Kelsey R.G., Moldenke A.F., Miller J.C., Berry R.E. \& WERNZ J.G. 1993: Effects of nitrogen and douglas-fir allelochemicals on development of the gypsy-moth, Lymantria dispar. - J. Chem. Ecol. 19: 1245-1263.

Kenward M.G. \& Roger J.H. 1997: Small sample inference for fixed effects from restricted maximum likelihood. - Biometrics 53: 983-997.

KRISCHIK V.A. \& DENNO R.F. 1983: Individual, population, and geographic patterns in plant defense. Chapter 14. In Denno R.F. \& McClure M.S. (eds): Variable Plants and Herbivores in Natural and Managed Systems. Academic Press, New York, pp. 463-512.

LÄhdesmäki P., Pakonen T., SAari E., Laine K., Tasanen L. \& Havas P. 1990: Changes in total nitrogen, protein, amino-acids and $\mathrm{NH}_{4}{ }^{+}$in tissues of bilberry, Vaccinium myrtillus, during the growing season. - Holarctic Ecol. 13: 31-38.

Laine K.M. \& HentTonen H. 1993: Phenolics/nitrogen ratios in the blueberry Vaccinium myrtillus in relation to temperature and microtine density in Finnish Lapland. - Oikos 50: 389-395.

LeRaut P. 2009: Moths of Europe. Vol 2. NAP Editions, Paris, $808 \mathrm{pp}$.

LinDROTH R.L. \& Bloomer M.S. 1991: Biochemical ecology of the forest tent caterpillar - responses to dietary protein and phenolic glycosides. - Oecologia 86: 408-413.

Osier T.L., Hwang S.-Y. \& LindRoth R.L. 2000: Within- and between-year variation in early season phytochemistry of quaking aspen (Populus tremuloides Michx.) clones in northern Michigan, U.S.A. - Biochem. Syst. Ecol. 28: 197-208.

Pinault L., Thurston G. \& Quiring D. 2009: Interaction of foliage and larval age influences preference and performance of a geometrid caterpillar. - Can. Entomol. 141: 136-144.

Porter J. 1997: The Colour Identification Guide to Caterpillars of The British Isles. Penguin. London, $288 \mathrm{pp}$.

Price P.W. 1997: Insect Ecology. 3rd ed. John Wiley \& Sons, New York, 888 pp.

Price M.L. \& ButLer L.G. 1977: Rapid visual estimation and spectrophotometric determination of tannin content of sorghum grain. - J. Agric. Food Chem. 25: 1268-1273.

RiIPI M., Ossipov V., Lempa K., Haukioja E., Koricheva J., Ossipova S. \& Pihlaja K. 2002: Seasonal changes in birch leaf chemistry: are there trade-offs between leaf growth and accumulation of phenolics? - Oecologia 130: 380-390.

Riipi M., Haukioja E., Lempa K., Ossipov V., Ossipova S. \& PihLAJA K. 2004: Ranking of individual mountain birch trees in terms of leaf chemistry: seasonal and annual variation. Chemoecology 14: 31-43.

Sandre S.-L., KaAsiK A., Eulitz U. \& Tammaru T. 2013: Phenotypic plasticity in a generalist insect herbivore with the combined use of direct and indirect cues. - Oikos [in press] doi: 10.1111/j.1600-0706.2013.00504.x.

SAS Institute Inc. 2009: SAS/STAT 9.2 User's Guide. 2nd ed. SAS Institute Inc., Cary, NC.

Schoonhoven L.M., van LoON J.J.A. \& Dicke M. 2007: InsectPlant Biology. 2nd ed. Oxford University Press, New York, NY, $421 \mathrm{pp}$.

SCRIBer J.M. \& SLANSKy F. 1981: The nutritional ecology of immature insects. - Annu. Rev. Entomol. 26: 183-211.

Stamp N.E. \& Bowers M.D. 1990: Phenology of nutritional differences between new and mature leaves and its effect on caterpillar growth. - Ecol. Entomol. 15: 447-454.

Steinbauer M.J. \& Matsuki M. 2004: Suitability of Eucalyptus and Corymbia for Mnesampela privata Guenee): (Lepidoptera: Geometridae) larvae. - Agric. For. Entomol. 6: 323-332.

SтоскноғF B.A. 1993: Ontogenetic change in dietary selection for protein and lipid by gypsy-moth larvae. - J. Insect Physiol. 39: 677-686.

Swain T. \& Hillis W.E. 1959: The phenolic constituents of Prunus domestica I. The quantitative analysis of phenolic constituents. - J. Sci. Food Agric. 10: 63-68.

TAMMARU T. 1998: Determination of adult size in a folivorous moth: constraints at instar level? - Ecol. Entomol. 23: $80-89$.

TAMMARU T. \& ESPERK T. 2007: Growth allometry of immature insects: larvae do not grow exponentially. - Funct. Ecol. 21: 1099-1105.

Vellau H. \& Tammaru T. 2012: Larval crowding leads to unusual reaction norms for size and time at maturity in a geometrid moth (Lepidoptera: Geometridae). - Eur. J. Entomol. 109: $181-186$.

Received January 30, 2013; revised and accepted April 29, 2013 